\title{
Orthotopic Liver Transplantation
}

National Cancer Institute

\section{Source}

National Cancer Institute. Orthotopic Liver Transplantation. NCI Thesaurus. Code C51696.

A surgical procedure in which an individual's native liver is removed and replaced by a donor liver. 